\title{
Preparation and Activity of Solid-State Hydrodesulfurization Catalysts
}

There has been much work done in the field of $\mathrm{MoS}_{2}$-based hydrodesulfurization catalysis trying to establish what phase is responsible for catalytic activity. Much of this research has focused on the effect of the Co promoter and whether its predominant contribution is of the electronic or structural nature. Schuit et al. (l) proposed that the promoter ions stabilize a molybdenum oxide monolayer which is responsible for the observed catalytic activity. Farragher and Cossee (2) postulated that the promoter was "pseudo-intercalated" between successive layers of $\mathrm{MoS}_{2}$ and that this structural change was accompanied by a surface reconstruction triggering HDS activity. Delmon et al. (3) argued in favor of $\mathrm{Co}_{9} \mathrm{~S}_{8}$ and $\mathrm{MoS}_{2}$ coexisting as the active species. In this "remote-control model" $\mathrm{H}_{2}$ is dissociatively adsorbed on the cobalt sulfide and transferred to the $\mathrm{MoS}_{2}$ surface where it then reacts with an adsorbed sulfur-containing compound. As another possible explanation for the promoter effect of Co or Ni, Pratt and Sanders (4) and Vrinat and co-workers (5) proposed that the promoter stabilizes very small particles of $\mathrm{MoS}_{2}$. This notion was also supported by more recent NMR experiments performed by Ledoux et al. (6). Topsøe and co-workers $(7,8)$ were able to correlate HDS activity with a unique but structurally difficult to define "Co-Mo-S" phase, in which it is hypothesized that the Co-promoter atoms lie at the edges of the $\mathrm{MoS}_{2}$ layers. More recent EXAFS work has provided evidence in support of this edgedecorated $\mathrm{MoS}_{2}$ species (9). Other researchers $(10)$ have put forward the notion that cobalt sulfide alone might have favor- able HDS characteristics. This concept was surprising since in previous studies the promoter sulfides had shown little activity ( 7 , 8). More recently Prins and co-workers have expressed doubt about the importance of a Co sulfide phase as the active phase (II). Theoretical work by Harris and Chianelli (12) has indicated that the promoter atom plays a role in determining the electronic state of the $\mathrm{MoS}_{2}$. Consequently, the increased HDS activity has been attributed to an electronic contribution from the promoter atom. According to this model, only $\mathrm{Ni}$ and $\mathrm{Co}$ showed a positive activity effect as they increased the electron density on Mo. Fe displayed little effect and $\mathrm{Cu}$ acted as a poison, essentially oxidizing Mo. Recently Ledoux et al. $(13,14)$ proposed the existence of two types of Co species at the edges of the $\mathrm{MoS}_{2}$ structurc, a distorted tetrahedral phase responsible for HDS activity and a rapid octahedral which they think acts as a glue, anchoring the tetrahedral phase to the $\mathrm{MoS}_{2}$. However, Prins et al. presented EXAFS work which does not support this hypothesis (11).

The present note reports the results of our attempt to grow unsupported bulk $\mathrm{P}-\mathrm{Mo}-\mathrm{S}$ (where $\mathrm{P}$ is $\mathrm{Fe}, \mathrm{Co}$, or $\mathrm{Ni}$ ) phases. The synthesis of these phases was based on solid-state reactions of elemental sulfur with metallic promoter and Mo powders. These bulk phases are easier to characterize than those in conventional supported HDS catalysts. Therefore, they offer a better opportunity for establishing correlations between stoichiometry, structure, and activity.

A series of samples with a limited $\mathrm{P} / \mathrm{Mo}$ ratio and a general stoichiometry of $\mathrm{P}_{0.05}$ 
TABLE 1

Surface Areas of Catalyst Samples

Catalyst

BET surface area $\left(\mathrm{m}^{2} / \mathrm{g}\right)$

\begin{tabular}{lr}
\hline $\mathrm{Fe}_{0.05} \mathrm{Mo}_{0.975} \mathrm{~S}_{2}$ & 14 \\
$\mathrm{Co}_{0.05} \mathrm{Mo}_{0.975} \mathrm{~S}_{2}$ & 26 \\
$\mathrm{Ni}_{0.05} \mathrm{Mo}_{0.95} \mathrm{~S}_{2}$ & 15 \\
$\mathrm{MoS}_{1.95}$ & 20 \\
$\mathrm{MoS}_{2}$ & 1 \\
\hline
\end{tabular}

$\mathrm{Mo}_{x} \mathrm{~S}_{2}$ (with $x$ being 0.975 or 0.95 ) was prepared by combining stoichiometric amounts of the elemental promoter and molybdenum powders with elemental sulfur, all three chemicals used being Fluka products (purum). The powders were thoroughly mixed by grinding them together to insure intimate contact between the components. The mixtures were placed into quartz tubes which were then evacuated to about $0.1 \mathrm{~Pa}$ and sealed. The tubes containing the mixtures were heated at a heating rate of $10 \mathrm{~K}$ per minute from room temperature to $783 \mathrm{~K}$, held at this temperature for $24 \mathrm{~h}$ and then rapidly quenched. Once the treatment was finished, the quartz tubes were opened. The contents of the tubes, generally dark grey or black materials, were removed and, if necessary, ground into fine powders. Based on their nominal composition the samples were named $\mathrm{Fe}_{0.05} \mathrm{Mo}_{0.975} \mathrm{~S}_{2}, \mathrm{Co}_{0.05} \mathrm{Mo}_{0.975} \mathrm{~S}_{2}$, and $\mathrm{Ni}_{0.05}$ $\mathrm{Mo}_{0.95} \mathrm{~S}_{2}$. Unpromoted $\mathrm{MoS}_{2}$ and a nonstoichiometric sample, $\mathrm{MoS}_{1.95}$ were also prepared from a mixture of metallic molybdenum and elemental sulfur following the procedure mentioned above. The surface areas of the freshly prepared samples were determined by using the BET method and a Monosorb Quantachrome Single Point Instrument with nitrogen as adsorbate (Table 1).

The catalytic activity for the hydrodesulfurization of thiophene (Aldrich $99+\%$, Gold Label) was measured in a $\frac{1}{4}$-in. diameter stainless-steel continuous-flow reactor. The powdered catalyst $(0.25-0.35 \mathrm{~g})$ was loaded into the reactor and the temperature raised to $673 \mathrm{~K}$ under a flow of high-purity helium at $20 \mathrm{ml}$ per minute and held at 673 $\mathrm{K}$ for $30 \mathrm{~min}$. Then, the temperature was lowered to the desired reaction temperature, typically between $473-673 \mathrm{~K}$. The He flow was replaced by a gaseous feed stream containing $2.7 \%$ (by volume) of thiophene, the balance being hydrogen, at a flow rate of $10 \mathrm{ml} / \mathrm{min}$ and atmospheric pressure. The high-purity $\mathrm{He}$ and $\mathrm{H}_{2}(<49$ ppm impurities) were further purified by passage through a commercial oxygen trap (Matheson) and a bed of molecular sieves ( $5 \AA$ ) to remove moisture.

The effluent from the reactor was analyzed by gas chromatography. Product separation and analysis were performed by using an $n$-octane/Porasil $\mathrm{C}$ column in a Varian 3700 gas chromatograph equipped with a thermal conductivity detector. Peak areas were determined by a HewlettPackard 3390A integrator.

At $523 \mathrm{~K}$ the activity trends for the model catalysts were $\mathrm{Ni}(30.0 \%)>\mathrm{Co}(6.3 \%)>\mathrm{Fe}$ $(5.7 \%)>\operatorname{MoS}_{1.95}(5.5 \%)>\operatorname{MoS}_{2}(<1 \%)$. The specific thiophene conversions for these materials are given in parentheses. At $573 \mathrm{~K}$ the activity trends for the model catalysts remained, but the differences became more pronounced. After $3 \mathrm{~h}$ on stream it was seen that the $\mathrm{Ni}_{0.05} \mathrm{Mo}_{0.95} \mathrm{~S}_{2}$ catalyst had a steady-state conversion just over $60 \%$, the $\mathrm{Co}_{0.05} \mathrm{Mo}_{0.975} \mathrm{~S}_{2}$ was in the mid-50\% range, $\mathrm{Fe}_{0.05} \mathrm{Mo}_{0.975} \mathrm{~S}_{2}$ was just over $40 \%, \mathrm{MoS}_{1.95}$ was near $30 \%$, and $\mathrm{MoS}_{2}$ was consistently below $1 \%$. At higher temperatures $(673 \mathrm{~K})$ conversions in excess of $90 \%$ were consistently observed for the promoted samples and $\mathrm{MoS}_{1.95}$.

The temperature dependence of the HDS activity for all the model catalysts is presented in Fig. 1a. The turnover frequencies (TOF) were expressed in terms of moles of thiophene converted per gramatom Mo per second. Again, it may be seen that the promoter trend of $\mathrm{Ni}>\mathrm{Co}>\mathrm{Fe}$ is observed in our solid-state system. Other researchers $(15,16)$ have reported similar findings, although $\mathrm{Fe}$-promoted catalysts 
a)

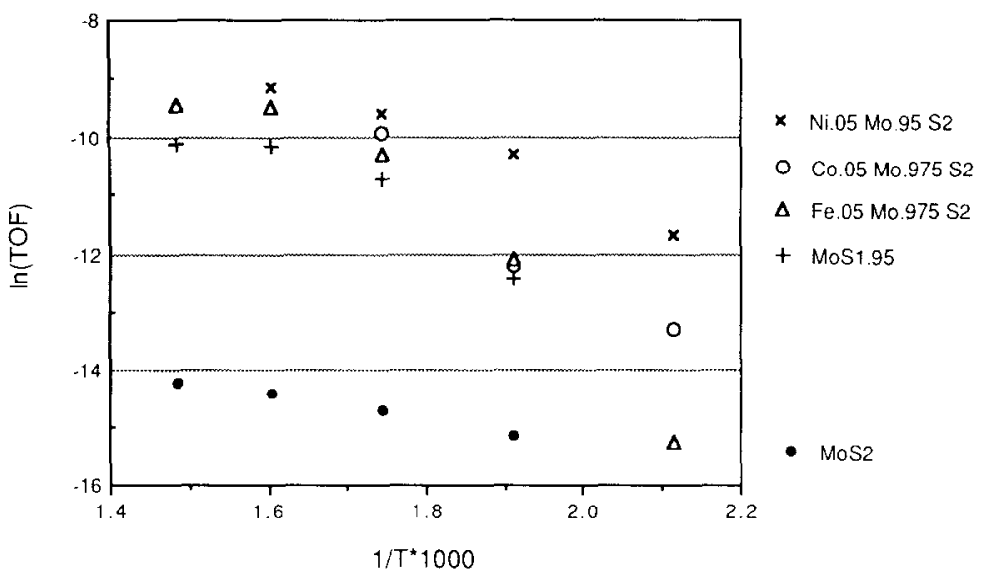

b)

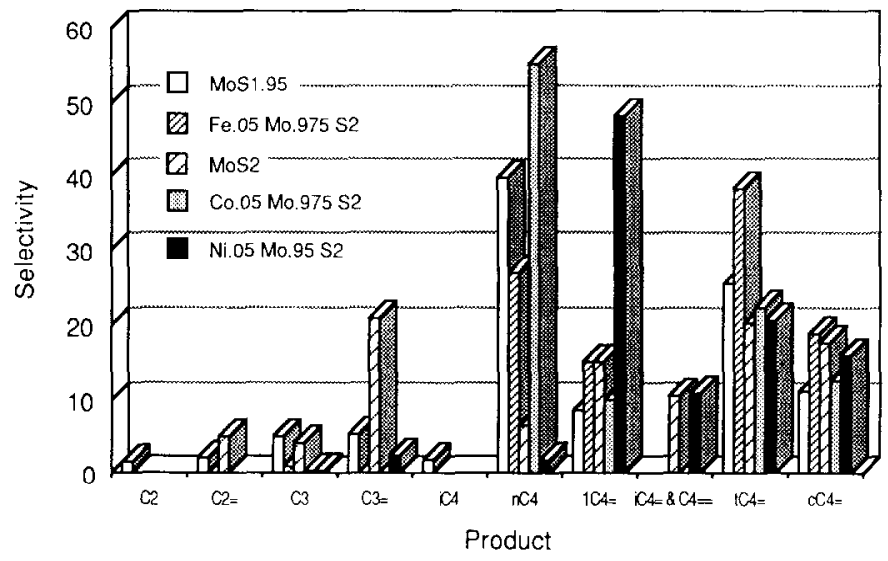

FIG. 1. (a) Temperature dependence of turnover frequencies (molecules of thiophene $/ \mathrm{mol} \mathrm{of} \mathrm{Mo/s)}$ for thiophene HDS over the various solid-state catalysts. (b) Product distributions obtained in thiophene HDS. The results shown were collected at $523 \mathrm{~K}$ on all samples, except for the $\mathrm{Ni}$-containing catalysts where data are shown for a temperature of $473 \mathrm{~K}$.

tend to have low activities. However, in our solid-state catalysts the promoting effect of $\mathrm{Fe}$ is far from negligible and is very close to that of Co. It should be noted that the substantial increase in HDS activity of these solid-state catalysts cannot be attributed solely to the presence of promoters. In fact, even in the absence of a promoter, significant increases in HDS activity could be achieved simply by introducing anionic sulfur vacancies into $\mathrm{MoS}_{2}$. Hence, one of the predominant roles of the promoter atom in these solid-state catalysts appears to be linked to the creation of sulfur vacancies.
Of course, this does not rule out that the promoter may have an additional secondorder effect beyond facilitating nonstoichiometry and sulfur deficiency in molybdenum sulfide.

Two possible scenarios for the formation of nonstoichiometric molybdenum sulfide could be envisioned. One is that the incorporation of lower charged promoter ions into the $\mathrm{MoS}_{2}$ lattice requires the introduction of sulfur vacancies to maintain electroneutrality. The second possibility could be that the promoter acts as a scavenger during catalyst synthesis. The formation of 
promoter bulk sulfides could thereby deplete the sulfur pool required for the formation of stoichiometric $\mathrm{MoS}_{2}$. In support of the second hypothesis, when presulfiding $\left(\mathrm{H}_{2} / \mathrm{H}_{2} \mathrm{~S}\right.$ at $673 \mathrm{~K}$ for $\left.24 \mathrm{~h}\right)$ a mechanical mixture of Mo and promoter powder bulk promoter sulfides were preferentially formed, leaving most of the Mo unreacted. At this point the relative contribution of each of these two scenarios is not yet clear.

The product distributions of the different hydrocarbons resulting from the hydrodesulfurization of thiophene are given in Fig. $1 b$. The data shown in this figure were collected at conversions less than $8 \%$ of the total thiophene fed. Isobutene and butadiene could not be separated under our experimental conditions and Fig. 1b shows the sum of these two products. Due to the higher activity of the Ni-promoted sample the reaction temperature was $473 \mathrm{~K}$ rather than the $523 \mathrm{~K}$ used for the other promoted catalysts in order to keep the conversion and TOF values roughly equivalent. It must be noted that product distributions tend to be not only a function of conversion but also of temperature. Therefore, the data shown in Fig. 1b should only be used for illustrating that our catalyst selectivities conform with those found typically in HDS catalysts under comparable reaction conditions.

Although each of the three promoters used in this study provided similar increases in activity, there are subtle differences in the product distributions. $\mathrm{Co}_{0.05}$ $\mathrm{Mo}_{0.975} \mathrm{~S}_{2}$ and $\mathrm{MoS}_{1.95}$ preferentially produced $n$-butane, $\mathrm{Fe}_{0.05} \mathrm{Mo}_{0.975} \mathrm{~S}_{2}$ favored the formation of trans-2-butene, $\mathrm{Ni}_{0.05}$ $\mathrm{Mo}_{0.95} \mathrm{~S}_{2}$ made primarily 1-butene, while $\mathrm{MoS}_{2}$ produced significant quantities of propylene, trans-2-butene, and cis-2butene. Only $\mathrm{MoS}_{2}$ and $\mathrm{Ni}_{0.05} \mathrm{Mo}_{0.95} \mathrm{~S}_{2}$ yielded any isobutylene or butadiene in the product stream, and only $\mathrm{MoS}_{1.95}$ produced any isobutane. Lighter products $(<C 4)$ were produced by all samples; however, they were never major (i.e., $>10 \%$ ) components, except in the case of propylene for the $\mathrm{MoS}_{2}$ sample. The high $n$-butane fractions seen for $\mathrm{Co}_{0.05} \mathrm{Mo}_{0.975} \mathrm{~S}_{2}$ and $\mathrm{MoS}_{1.95}$ are likely due to an increased $\mathrm{H}_{2}$ transport capability resulting from the presence of unreacted Mo in the catalyst synthesis charge. Vrinat et al. (17) have shown that $\mathrm{Ni}$ has grcater hydrogenation activity than Co. However, in our case the Ni catalyst was run at a lower temperature than the other samples and thus this characteristic hydrogenation trend was not as pronounced. At higher temperatures (i.e., $>523 \mathrm{~K}$ ) all the promoted samples produced predominantly $n$-butane. As interesting as these subtle trends may be, they are not the focus of this note and a more detailed kinetic analysis will be required to fully explain the observed differences.

It is important to note that more active samples consistently had larger surface areas than that of the lower activity $\mathrm{MoS}_{2}$ (Table 1). However, a normalization of activity based on BET surface area would not be meaningful in view of the lack of correlation between HDS activity and surface area previously reported $(18-20)$. Within the HDS research community, a consensus seems to be developing that a normalization based on edge area might be more desirable. However, to accurately determine the edge area is not a trivial task. In the case of our solid-state catalysts, high-resolution electron microscopy showed that the exposed basal planes of $\mathrm{MoS}_{2}$ containing the Mo ions remain undisturbed when promoters are introduced. In striking contrast to that, other exposed crystallographic orientations containing sulfur ions, which could be considered "edge areas," show significant structural disorder. From the lack of long-range order in these planes we can infer surface roughening on an atomic scale and the presence of sulfur vacancies. Figure 2 illustrates the structural effect of the promoter $\left(\mathrm{CO}_{0.05}\right.$ $\mathrm{Mo}_{975} \mathrm{~S}_{2}$ ) on these planes compared with that of stoichiometric $\mathrm{MoS}_{2}$. The microscopic observations are in excellent agreement with XRD results showing preferential 

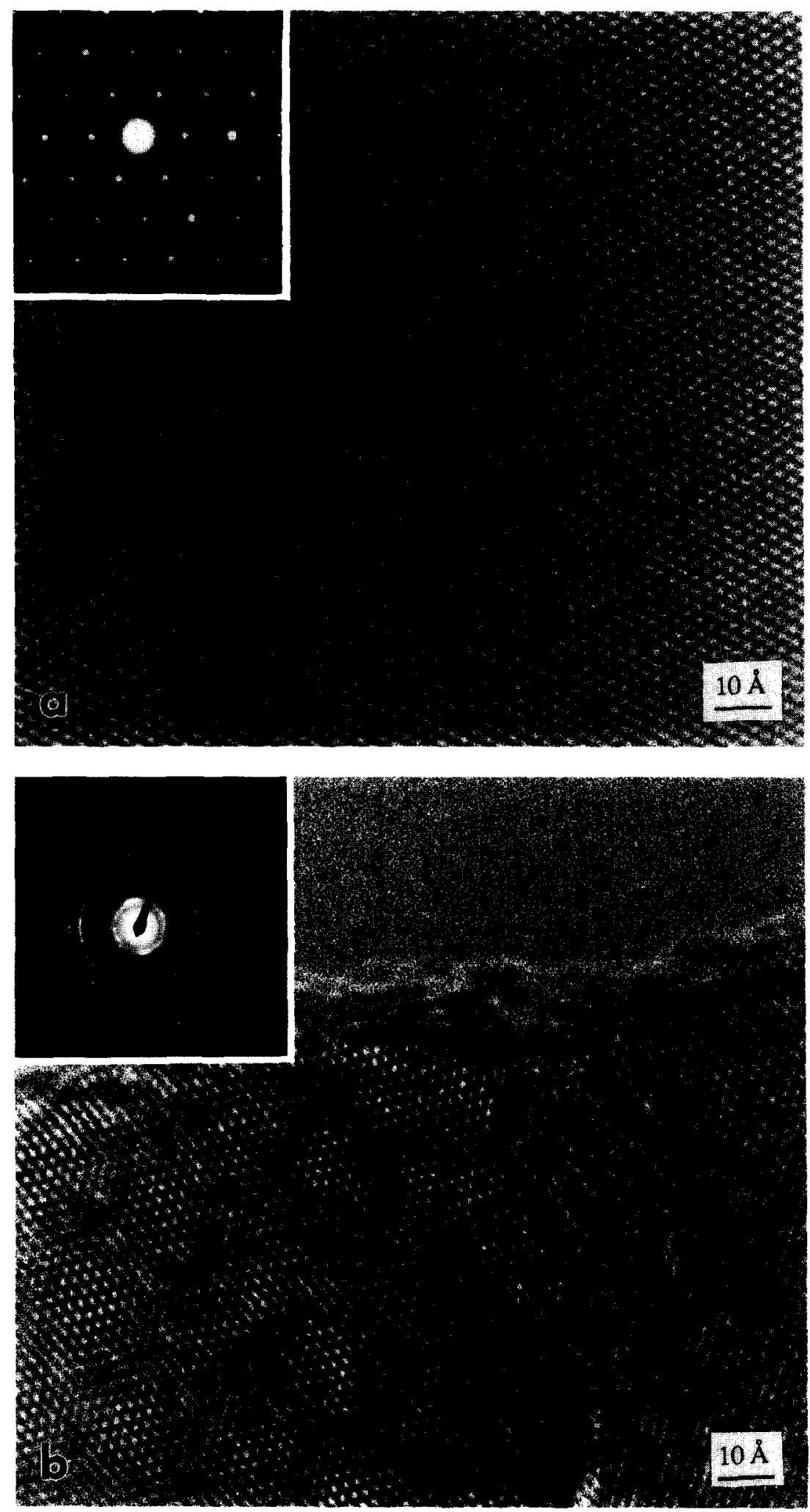

FIG. 2. Examples of high-resolution transmission electron micrographs obtained on a JEOL 4000EX microscope. Inset: Selected area diffraction pattern. (a) Well-oriented $\mathrm{MoS}_{2}$ (stoichiometric) structure showing the 2.74 and $2.69 \AA$ lattice planes, (b) Disordered "edge" structures in the cobalt-containing catalyst. 
broadening of reflections arising from sulfur-containing planes.

\section{ACKNOWLEDGMENTS}

M. A. Villa-Garcia wishes to express her gratitude to the MEC/Fulbright Committee for financial support. The authors also wish to thank Dr. John Mansfield of the Electron Microbeam Analysis Laboratory at the University of Michigan for helpful discussions relating to electron microscopy.

\section{REFERENCES}

I. Schuit, G. C. A., and Gates, B. C., AIChE J. 19, $417,1973$.

2. Farragher, A. L., and Cossee, P., in "'Proceedings, 5th International Congress on Catalysis, Palm Beach, 1972' (J. W. Hightower, Ed.), p. 1301. North-Holland, Amsterdam, 1973.

3. Pirotte, D., Zabala, J. M., Grange, P., and Delmon, B., Bull. Soc. Chim. Belg. 90, 1239, 1981.

4. Pratt, K. C., and Sanders, J. V., in "Proceedings, 7 th International Congress on Catalysis, Tokyo, 1980" (T. Seyama, and K. Tanabe, Eds.), p. 1420. Kodansha/Elsevier, Amsterdam/Tokyo, 1981.

5. Vrinat, M. L., and De Mourgues, Appl. Catal. 5, 43, 1983.

6. Ledoux, M. J., Maire, G., Hantzer, S., and Michaux, O., in "Proceedings, 9th International Congress on Catalysis, Calgary, 1988' (M. J. Phillips and M. Ternan, Eds.), p. 74. Chem. Institute of Canada, Ottawa, 1988.

7. Topsøe, H., Clausen, B. S., Candia, R., Wivel, C., and Mørup, S., J. Catal. 68, 433, 1981.

8. Wivel, C., Candia, R., Clausen, B. S., Mørup, S., and Topsøe, H., J. Catal. 68, 453, 1981.

9. Topsøe, H., Clausen, B. S., and Mørup, S., Hyperfine Interact. 27, 231, (1986).

10. Duchet, J. C., van Oers, E. M., de Beer, V. H. J., and Prins, R., J. Catal. 80, 386, 1983.

11. Prins, R., Bouwens, S. M. A. M., Koningsberger, D. C., and de Beer, V. H. J., "EXAFS and XPS of Sulfided $\mathrm{Co}(\mathrm{Ni})-\mathrm{Mo} / \mathrm{C}$ and $\mathrm{Co}(\mathrm{Ni})-\mathrm{Mo} / \mathrm{Al}_{2} \mathrm{O}_{3}$ Catalysts," 11th North American Meeting of the Catalysis Society, Dearborn, MI, May 7-11, 1989.
12. Harris, S., and Chianelli, R., J. Catal. 98, 17, 1986.

13. Ledoux, M. J., Michaux, O., Agostini, G., and Panissod, P., J. Catal. 96, 189, 1985.

14. Ledoux, M. J., Michaux, O., Agostini, G., and Panissod, J. Catal. 102, 275, 1986.

15. Göbölös, S., Wu, Q., Andre, O., Delannay, F., and Delmon, B., J. Chem. Soc. Faraday Trans. I 82, 2423, 1986.

16. Göbölös, S., Wu, Q., Delannay, F., and Delmon, B., Polyhedron 5, 219, 1986.

17. Vrinat, M., Lacroix, M. Breysse, M., and Frety, R,, Bull. Soc. Chim. Belg. 93, 697, 1984.

18. Tauster, S. J., Percoraro, T. A., and Chianelli, R. R., J. Catal. 63, 515, 1980.

19. Furimsky, E., Catal. Rev. Sci. Eng. 22(3), 371, 1980.

20. Villa Garcia, M., Lindner, J., Sachdev, A., and Schwank, J., J. Catal., in press.

J. LINDNER

A. SACHDEV

Department of Chemical Engineering

The University of Michigan

Ann Arbor, Michigan 48109-2136

\section{A. Villa Garcia}

Department Química Organometálica

Facultad de Química

Universidad de Oviedo

Oviedo-33071, Spain

J. SchWANK

Department of Chemical Engineering

The University of Michigan

Ann Arbor, Michigan 48109-2136

Received May 22, 1989; revised August I, 1989 